\title{
Pre-service Teachers' Collaborative Learning Experiences in a Science Content Course
}

\author{
Mahsa Kazempour $^{1 *}$, Aidin Amirshokoohi \\ ${ }^{1}$ Department of Early Childhood and Elementary Education, Penn State Berks, Reading Pennsylvania, USA, ${ }^{2}$ Department of Education, DeSales \\ University, Center Valley, Pennsylvania, USA
}

*Corresponding Author: muk30@psu.edu

\section{ABSTRACT}

Developing an in-depth understanding, skills, and level of comfort to teach through inquiry requires that pre-service teachers themselves learn through an inquiry-based approach that would allow them to explore various dimensions of such an approach. Productive discourse and collaboration, involving extensive interactions among students, constant and mutual exchange of ideas, and higher-order thinking are critical components of inquiry-based learning. Further research is needed to understand the dynamics of collaborative experiences and the process by which science is learned in collaborative team contexts, particularly with teacher candidates who will be responsible for implementing such approaches in their future classrooms. This qualitative study aimed to explore the dynamics of inquiry-based learning experiences of two teams of elementary pre-service teachers in an introductory science content course. Analysis of observation data indicated that although the team engaged in a less structured activity engaged in slightly more productive communication, both teams experienced inequitable levels of involvement by different team members. Team members assumed different roles and varying degrees of participation and engagement in discourse. Our research indicated possible challenges of collaborative interaction and discourse which are critical to consider as teacher educators and researchers. It is imperative that science content and methods courses offer preservice teachers opportunities for direct experience and explicit instruction on effective means of productive interactions and discourse.

KEY WORDS: inquiry; collaborative learning; science discourse; team interactions; pre-service teachers

\section{INTRODUCTION}

S cience education in elementary grades is critical in developing a scientific literate society and teachers play an insurmountable role in this process. Learning about and through inquiry has been a focus of science education reform since the release of the National Science Education Standards (NRC, 1996). Yet, elementary teachers have been shown to teach science as they were taught or avoid teaching science due to their negative attitudes and low confidence with respect to learning and teaching science (Appleton, 2003; Fitzgerald et al., 2013). Studies focusing on pre-service teachers' experiences with science teaching and learning, especially in terms of inquiry-based learning and instruction, remain relatively scarce. Since elementary pre-service teachers typically lack prior experiences with inquiry-based learning during in their K-12 education (Kazempour, 2014), developing an in-depth understanding, skills, and level of comfort to teach through inquiry requires that pre-service teachers themselves learn through an inquiry-based approach that would allow them to explore various dimensions of such an approach (Bergman and Morphew, 2015; Bleicher, 2009). Beliefs, attitudes, and self-efficacy toward inquiry-based teaching science have been shown to be related to these constructs in terms of inquiry-based learning (Kazempour and Sadler, 2016). Science understanding is socially constructed as students attempt to make meaning through discourse, communicating ideas, and resolving conflicts. Authentic science inquiry experiences require students to engage in collaboration and communication, like what scientists engage in as they examine questions, gather evidence, and attempt to understand natural phenomena (Duschl and Schouse, 2007; Kazempour, 2018). Productive discourse and collaboration, involving extensive interactions among students, constant and mutual exchange of ideas, and higher-order thinking have been shown to enhance students' achievement, problem-solving skills, motivation, and social interactions (Gillies et al., 2014). However, as noted by Woods-McConney et al. (2016), the extent and effectiveness of such collaborative inquiry experiences are not fully understood, and further research is necessary to better understand student experiences and identify effective collaborative learning strategies.

Collaboration consists of sociocultural dimension, continued negotiation of norms, status, and identities. Although collaborative teamwork has been touted by the science education community and supported by empirical research (e.g., NRC, 1996; O'Donnell, 2006) and is more commonplace now in today's classrooms, further research is needed to understand the dynamics of "the joint coordination of group shared task work, and multiple perspectives" (Rogat and Adams-Wiggins, 2014, p. 880) and the process by which science is learned in collaborative team contexts. 


\section{PURPOSE}

This qualitative study aimed to explore the dynamics of inquiry-based learning experiences of elementary pre-service teachers in an introductory science content course. Our goal was to examine interaction patterns, roles, and levels of engagement of students within the team, as well as possible challenges and obstacles facing individuals or the entire team and ways in which members of the team engaged in disagreement resolution. We specifically focused on two teams and two activities, a direct and a guided inquiry one, to gauge whether there would be any distinctions in the extent or type of interactions.

\section{METHODOLOGY}

\section{Context}

This study examined the experiences of pre-service teachers enrolled in a required science content course for elementary education majors at a large Midwestern University in the United States. The course focused on physical and chemical science concepts with emphasis on science practices such as making observations, asking questions, and gathering, and analyzing data. The course had a weekly 1 -h lecture component and a lab component that met twice a week. Each 2-h lab session began with an instructor-led discussion, followed by instructions on the day's activity, and then the remainder of the class session was spent on team collaboration on completing the tasks.

The focus of the current study was on two activities that were tweaked to different degrees and were the focus of two different class sessions. One activity, which occurred earlier in the semester and involved becoming familiar with making mass measurements, was a structured activity that was tweaked only to a small degree to include more questions for students to think about. It was still prefaced by a teacher-led discussion and text reading on mass and units of measurement for mass. The other activity dealing with the concept of density was modified more extensively and included more open-ended sections for students to think about and devise plans for finding the volumes of different items, explaining the sinking and floating mechanisms, and understanding the concept of density as the relationship between the volume and mass of objects.

The lab section consisted of 16 students, two males and fourteen females, working in teams of four. The authors informed the students about the study and the need to audio and video record the lab sessions for analysis. Two-thirds of the class signed the consent form administered a week before the in-class observations. We decided to focus on two teams of students, one from each class session, consisting of four students seated at the same table who had provided consent to participate in the study. One team consisted of four female students and the other team consisted of one male and three female students, all in their $2^{\text {nd }}$ year of the program. From the student information sheets that the instructor shared with us and the brief conversations that we had with these students, they indicated that this course was the first science content course they had enrolled in during college and that during high school, they experienced traditional lecture-based science classes. Hence, for all of them, this was their first opportunity to be engaged in student-centered science activities through an inquiry approach in a cooperative learning setting.

\section{Data Collection and Analysis}

Qualitative research examining participant interactions and experiences in social settings often involve observational record or field notes that consist of detailed and concrete descriptions (Creswell, 2007). We decided to explore participants' actions and interactions during these two inquiry sessions using observation data and field notes to collect detailed descriptions and reflective notes that were later analyzed for possible patterns and themes.

Each team discussion was recorded using a digital video camera and a digital audio recorder to allow for easy transcription of the team members' communication. We each also completed field notes during our observation of the class sessions. We arrived in the classroom $15 \mathrm{~min}$ before the beginning of the class and set up the video camera at the back of the classroom and within several feet of the table that the team was seated at. We placed the audio recorder in the middle of the table to record their conversations in addition to what would be captured in our field notes and the video recordings. We were seated near the video camera so that we could observe the team unobtrusively, take field notes, and adjust the camera when necessary.

The audio and video recordings of the participants' verbal communications were fully transcribed, and we utilized the video recordings and our field notes to add comments regarding participant gestures, facial expressions, and body language. We then read through the transcripts several times, coded the data, and explored emerging patterns with respect to student roles, interactions among members, and power analysis within each team and then across both teams (Carspecken, 1996).

\section{RESULTS AND DISCUSSION}

We will discuss the findings pertaining to each team by first sharing an excerpt of their dialogue, followed by an analysis of the individual member's roles and overall group interaction patterns. The results section will end with a cross-case analysis discussing the comparison between the two groups, referred to as "cases." Participant names included in this section are pseudonyms.

\section{Case 1: Measuring Mass - Structured Activity}

Everyone except Mary reached in the tray and picked up one of the items to be measured. Mary and Jamie were looking down at their textbooks while Katie and Lisa sat there looking at the two teammates across the table. The following is a brief excerpt of their discussions and interactions during the session (Excerpt 1). 


\section{Member roles}

The role analysis of the full observation data for this class session illuminated interaction dynamics occurring in this team and the roles assumed by the different members, as evident in Excerpt 1.

\section{Mary}

Throughout the lab, Mary was quiet and timid about sharing her answers or ideas with the others in the team and would wait until asked by teammates before attempting to speculate about something. Mary constantly played the part of the clueless team

Mary: Points to her text. 'It says we have to estimate the mass of these things and I have

nooooooo idea how to estimate!' She giggles and looks at Katie and Lisa who smile.

Jamie: Reads aloud the instructions 'Take a test tube and a pencil and clip and find the mass. Okay, but we have to estimate first.'

Lisa: 'Let's just guess starting with the test tube.' Holds the test tube in the palm of her hand and feels it before handing it to Jamie.

Jamie: Holds the test tube in the palm of her hand moving her hand slightly up and down. 'I think this is about 3 grams.'

Mary: Grabs the test tube and just giggles. (Pause). 'I don't know. I am really not good at this.' Shrugs shoulders and marks something on her paper while others remain silent.

Lisa: 'I have a paper clip if you guys want because that is one gram, right?' She finds a small clip in her pocket and puts it on the table.

Mary: 'Wait, what did you say?'

Lisa: 'The paper clip is supposed to be one gram.' She mumbles as she starts playing with the paper clip. She puts the paper clip in the palm of one hand and the test tube in the other and moves her hands up and down like a scale.

Jamie: Picks up the two items and then looks at Katie while weighing them in her hand. 'It's not very heavy though. Because (short pause), here (extends arm out to Katie) feel it - that's what I got out of it.'

Katie: Quickly feels the items and puts them down on the table and says 'yeah'.

Jamie: Starts marking her paper with her pencil 'Okay let's say it's 3 and just measure it.'

Katie and Lisa have the balance facing them. Mary puts the test tube in the pan of the balance. Katie and Lisa start moving the riders on the balance.

Jamie: Stands up and tries to get a glimpse of the balance from where she is. She waves her pencil out towards Katie and Lisa as if to grab their attention and then points to the balance. 'So, shouldn't we zero it first?' Katie and Lisa both look up and face each other and giggle. Lisa starts zeroing the balance. 'Oh yeah! We will do that now.'

Jamie: 'But wait. Don't we also have to remove the test tube, zero it first, then put it back?' Without waiting for an answer, she stretches her arm out and grabs the test tube from the balance tray. Lisa nods twice and continues zeroing the balance. 'Okyeah that's zeroed.'

Jamie: Walks over and stands behind Lisa and Katie. She then extends her arm toward the balance and says, ' $I$ think for this last beam we need to use the tip of a pencil or our nails because it is sensitive.' Katie and Lisa move back and allow Jamie to move the riders. They both look and smile at each other.

Jamie: 'Now we have to weigh the pencil. The pencil's probably like 9 or 10.'

Katie: Cuts in as Jamie is about to continue. 'Yeah, but it shouldn't weigh very much though' (she picks up the pencil from the table and feels it in her right palm).

Lisa: Smiles and leans forward on the table. 'I think that it weighs a lot less too!'

Jamie: 'Really?' She then looks over to Mary, but Mary is busy marking something on her paper. Jamie then looks at Katie and Lisa and says 'Okay, let's find out!'

Lisa: Taps on Mary's paper a couple of times with her pen as if to get her attention. 'So, what do you think?'

Mary: stops writing and looks up at the pencil Lisa is now holding up, ' 5 maybe?' She shrugs her shoulders and smiles. 
member who either remained quiet or appeared puzzled or voiced confusion and inability to contribute to team discussion. Mary's demeanor suggested that she was mainly inattentive and uninvolved in the team tasks. She would sometimes sit back and watch as the other members while at other times kept herself busy looking down or writing in her notebook. This may have stemmed from her low self-esteem and confidence in the subject matter. Alternatively, based on her comments, her reserved demeanor may have been a means to avoid becoming too involved in a task she felt insecure about or answering questions she believed she did not know the answers to.

\section{Jamie}

Jamie was very confident in her demeanor. She answered the questions swiftly and without hesitation. She naturally took over and measured items or carried out instructions while other team members seemed confused, sat idle, or were too timid to attempt anything. She would also make sure her teammates were performing the task accurately and even intervened a couple of instances to point out errors or missteps such as the case with Katie and Lisa not zeroing the balance or accounting for the original mass of the container. Jamie worked meticulously and carefully followed the instructions. For instance, she would read the balance to the nearest thousandths and made the other team members in her team impatient. Jamie remained serious and attentive to the task even when the other members giggled, smiled, and laughed together.

\section{Katie and Lisa}

Katie and Lisa were also quiet, but they were relatively more involved in the task and discussion than Mary. However, for most of the task, they complied with Jamie's plans or simply confirmed and agreed with her answers without questioning anything. For instance, when finding the mass of the object on balance, they listened to her suggestion about zeroing the balance and afterward moved aside for her to read the balance without inquiring about what she was doing. There was, however, a unique moment during the task when Katie and Lisa seemed to have become a pair that was prepared to question Jamie, but they did so without clearly opposing her. When estimating the mass of the test tubes, they made certain to provide similar estimates that were different from Jamie's estimate and tried to get Mary to agree with them to form a consensus.

\section{Case 2: Exploring Density - Guided Activity}

The instructor discussed the material from the previous lab and introduced a few topics related to the current lab through a brief class discussion. Then, the students began the activity by tearing out the appropriate lab pages in their textbook and getting their trays of material. Excerpt 2 includes part of their discussions and interactions during the session.

\section{Member roles}

The role analysis of the full observation data for this class session illuminated interaction dynamics occurring in this team and the roles assumed by the different members, as evident in Excerpt 2.

\section{Ellie}

Ellie's interactions and comments throughout the activity were reminiscent of a deep, reflective individual and a dominating and direction setting leader. She displayed her dominating personality in leading the team in an evasive manner, which would typically go unnoticed without meticulous observations and analysis. Even though Linn may have appeared as though she was leading the team with her fast pace, it was Ellie who would question what was going on, formulate counterarguments to Linn and stop her from thoughtlessly and quickly moving ahead, and encouraged everyone to see a more reasonable answer. In this way, she set and changed the direction of the team throughout the activity. Ellie was not satisfied with simple, quick answers that satisfied Linn. She often reflected on previous labs and learning and brought up issues to be discussed. She would question Linn's thinking. Even when she would briefly become quiet, she thought to herself and came back with more evidence to back up what she was saying.

\section{Linn}

Linn was quick to speak and point out things that perhaps did not seem to be going in the "right" direction, according to her. She often showed resistance to Ellie's suggestions and comments about the obtained results. She seemed to be critical of Ellie probably because she wanted to make sure that she and her team were doing everything "correctly" to prevent possible loss of points on the task. Her gestures, posture, and tone of voice indicated a high level of confidence and a desire to do things her way and not surrender to Ellie's objections. Linn appeared to want to progress swiftly through the questions to complete the task quickly and did not think about or wish to discuss the questions in-depth. Her grasp of the ideas appeared limited and her quick pace prevented her from completely absorbing the ideas and concepts that were discussed. Her demeanor gave the impression that she was inattentive and uninterested in her team's discussion and often ignored their comments as if not having even heard them. Despite her interest in speed, she also showed constant concern about writing the "right" answer and having team consensus in terms of written responses. She seemed to be obsessed with points and extrinsically motivated by grade and even emphasized once that the instructor would want all of them to have the same answer.

\section{Garrett and Kayla}

Garrett and Kayla demonstrated similar behaviors during the activity. Both were mainly quiet and listened passively to Ellie and Linn's discussions and consented to what they would deem necessary and appropriate for the team without questioning their judgment. They appeared to be mainly nonexistent in most of the discussions that occurred between the other two members. There were a few minor instances where they felt the urge to speak out and share their own perception 
and interpretations of the lab results only to be ignored or overshadowed by Ellie and Linn's discussions. Garrett occasionally attempted to join the conversation or use humor to bring some levity to the tense discussions between Linn and Ellie. Starting from the beginning of the activity, Kayla's role was limited to reading aloud the instructions and writing down what others were saying.

\section{Group Interaction Dynamics}

Power analysis of the team interactions within each group and across both cases revealed several points. In both cases,

Kayla: Reading aloud the instructions. 'If a thick liquid is poured over a thin liquid which do you think will float on top of the other?'

Linn: 'The thick liquid floats because when you put oil on water it floats. Right?'

Kayla: Playing with her hair gazes at Linn with a confused look. 'Ummm. But how, how do you know that oil is really thicker than water?'

Garrett: 'I think a thicker liquid will stay on top of the thinner one.'

Linn: Looks over at Garrett. 'Why?'

Garrett: 'Because it's all about visssscosssity.' Smiles. 'I don't know. 'Others smile too.

Linn: Looks right ahead at Kayla. 'No I think it has to do with density.'

Ellie: 'But... (short pause) wouldn't that mean that the liquid is less, like what we did yesterday. what was it? If it was less dense then it would float and if it were more dense it would sink?'

Linn: Looks over at Kayla and slightly shakes her head. 'So, let's just go with that for our prediction because we don't know if the other way would be correct.'

Ellie: Looks over at Linn and Kayla. 'So, a thicker liquid is more dense? Do you think thinner liquids aren't?' Shakes her head. 'But I don't think that. I think that thicker liquid will float on top of thinner liquids.'

Linn: 'But that's just because you know that.'

Ellie: 'There is nothing wrong with that. If you are just making predictions, you are saying that's what you think is going to happen.'

Linn: Cuts Ellie short. 'You could just make it up. Because you have no idea why.'

Garrett: 'It might be based on... '(cut short by Linn who starts talking to Ellie so he just finishes his sentence by turning to Kayla) 'the whole viscosity density thing and that the two of them might not be the same.'

Ellie: Gestures with her right hand to the paper and looks directly at Linn. But you have no idea that it would sink either. (emphasizes "either").

Linn: Looks at Ellie with her eyes wide open. 'Because it's denser. That's what we learned on Monday.'

Ellie: 'But how do you know that it is denser? (short pause) Just because a liquid is thick it's not denser. (short pause) We found out on Monday that, what's the density of water or whatever. We didn't figure out what a thick liquid's density is.'

Linn: continues with her sentence from before and doesn't allow Ellie to finish her sentence. 'With more water it was a higher density. Just because it weighs more it has a higher density. So I think a thicker one weighs more than a thinner one.'

Ellie: 'Just how are we going to prove what you are saying?

Linn: Because of what we did on Mondayyyy (emphasis)... because on Monday what we got was that things that are less dense (cut short by Ellie)

Ellie: looks at Linn but it had nothing to do with thick and thin liquids. I understand what you are saying that something that's less dense is going to float and that something that is more dense will sink. But we are dealing with coke cans which are heavier than what you think and they will sink. I just don't understand how, how you are explaining either of them in writing.'

Linn: I am going to write you would think (emphasizes it) just because that something that is more dense it would sink how-ever (emphasis and raised voice) you know that if you pour oil on water it floats. 
even though no formal roles and responsibilities were assigned to team members, an informal contractual power was witnessed whereby different team members assumed different roles throughout the activities. Although members such as Katie, Lisa, and Mary in the first case and Garrett and Kayla in the second case certainly did not appear to fully enjoy taking part in the various tasks, they nevertheless continued to contribute in some way. This type of informal contractual collaborative behavior may have been due to the heavy emphasis of the course on successful and continuous collaborative teamwork.

The team interactions were also suggestive of traditional normative power. Members appeared to work as a team and attempt to participate in different aspects of the activity, even if minor because they felt it would be the right thing to do. None of the members appeared to be indolent or opportunistic individuals who would purposefully make others do the work. Furthermore, they mostly succumbed to the leadership of one or two members with little questioning of their reasoning. Mary felt uncomfortable and indifferent in the lab setting. Most of the time, she was either not attentive to what was happening in the group or had very little to say about it. In the second team, Garrett and Kayla basically gave into the empowering roles of Ellie and especially Linn. They remained silent as many students do when one or two other students take over and talk very confidently about the task.

\section{IMPLICATIONS}

Engaging in scientific discourse as part of inquiry-based learning experiences enhances students' understanding (Gresalfi et al., 2012). Teachers play a crucial role in providing opportunities for inquiry-based and collaborative learning experiences for students and need to be able to model such practices themselves (McNeill and Krajcik, 2008; Woods-McConney et al., 2016) which can only occur if they have the necessary knowledge, skills, and pedagogical understanding about collaborative learning. Collaboration and communication, vital components of learning about and through inquiry, are critical for stimulating reflection, which is critical in shaping changes in pre-service teachers' attitudes, beliefs, and confidence levels. Therefore, it is critical to focus research on understanding the dynamics of inquiry-based learning experiences and identifying the social context and interactive patterns that pre-service teachers engage in. Our research indicated challenges with equitable interactions (Bianchini, 1997), where some members were less active than others and the level of discourse was therefore not as productive as possible. It is critical that teacher education courses, particularly science content and methods courses, offer pre-service teachers, opportunities for direct experience, and explicit instruction on effective means of productive interactions and discourse that are necessary for the social construction of understanding (Summers and Volet, 2010).
Additional studies are necessary to understand further the dynamics of the collaborative experiences of pre-service teachers. We intend to follow-up this study with another that will include observing multiple groups of students to ascertain the extent to which the observations in the current study pertaining to member roles and team interactions apply in other contexts. The study will also include subsequent interviews with participants to gain further insight into their thoughts and feelings during the group activities and how they each viewed their own roles and the team interaction in general. During the interviews, participants will also be shown sample video segments of their team interactions to aid in their discussion of the group dynamics.

\section{REFERENCES}

Appleton, K. (2003). How do beginning primary school teachers cope with science? Toward an understanding of science teaching practice. Research in Science Education, 33(1), 1-25.

Bergman, D.J., \& Morphew, J. (2015). Effects of a science content course on elementary pre-service teachers' self-efficacy of teaching science. Journal of College Science Teaching, 44(3), 73-81.

Bianchini, J.A. (1997). Where knowledge construction, equity, and context intersect: Student learning of science in small groups. Journal of Research in Science Teaching, 34, 1039-1065.

Bleicher, R. (2009). Variable relationships among different science learners in elementary science methods courses. International Journal of Science and Mathematics Education, 7(2), 293-313.

Carspecken, P. (1996). Critical Ethnography in Educational Research: Atheoretical and Practical Guide. London: Routledge.

Creswell, J. (2007). Qualitative Inquiry and Research Design: Choosing Among Five Approaches. New York: SAGE.

Duschl, R.A.D., \& Shouse, A.W. (2007). Taking Science to School: Learning and Teaching Science in Grades K-8. Washington, DC: National Academies Press.

Fitzgerald, A., Dawson, V., \& Hackling, M. (2013). Examining the beliefs and practices of four effective Australian primary science teachers. Research in Science Education, 43, 981-1003.

Gillies, R., Nichols, K., Burgh, G., \& Haynes, M. (2014). Primary students' scientific reasoning and discourse during cooperative inquiry-based science activities. International Journal of Educational Research, 63, 127-140.

Gresalfi, M.S., Barnes, J., \& Cross, D. (2012). When does an opportunity become an opportunity? Unpacking classroom practice through the lens of ecological psychology. Educational Studies in Mathematics, 80(1), 249-267.

Kazempour, M. (2014). I can't teach science! A case study of an elementary pre-service teacher's intersection of science experiences, beliefs, attitude, and self-efficacy. International Journal of Environmental and Science Education, 9(1), 77-96.

Kazempour, M. (2018). Elementary preservice teachers' authentic inquiry experiences and reflections: A multicase study. Journal of Science Teacher Education, 29(7), 644-663.

Kazempour, M., \& Sadler, T. (2015). Supporting changes in pre-service elementary teachers' beliefs, attitudes, and self-efficacy regarding science and the teaching of science: A multi-case study. Teaching Education, 26(13), 247-271.

McNeill, K.L., \& Krajcik, J. (2008). Scientific explanations: Characterizing and evaluating the effects of teachers' instructional practices on student learning. Journal of Research in Science Teaching, 45(1), 53-78.

National Research Council (NRC). (1996). National Science Education Standards. Washington, DC: National Academy Press.

O'Donnell, A.M. (2006). The role of peers and group learning. In: Alexander, P.A., \& Winne, P.H., (Eds.), Handbook of Educational Psychology. New Jersey: Lawrence Erlbaum Associates Publishers. pp. 781-802.

Rogat, T.K., \& Adams-Wiggins, K.R. (2014). Other-regulation in 
Science Education International

31(4), 379-385

https://doi.org/10.33828/sei.v31.i4.6

Kazempour and Amirshokoohi: Pre-service collaborative learning experiences

collaborative groups: Implications for regulation quality. Instructional Science, 42(6), 879-904.

Summers, M., \& Volet, S. (2010). Group work does not necessarily equal collaborative learning: Evidence from observations and self-reports.
European Journal of Psychology of Education, 25(4), 473-492.

Woods-McConney, A., Wosnitza, M., \& Sturrock, K. (2016). Inquiry and groups: Student interactions in cooperative inquiry-based science. International Journal of Science Education, 38(5), 842-860. 